Article

\title{
Electrolyte Intake and Major Food Sources of Sodium, Potassium, Calcium and Magnesium among a Population in Western Austria
}

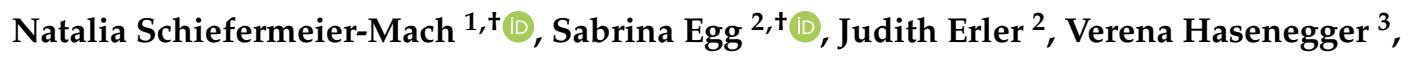 \\ Petra Rust $^{3}$ (D) Jürgen König ${ }^{3}$ ad and Anna Elisabeth Purtscher ${ }^{2, *}$ \\ 1 Department of Health Care and Nursing, FH Gesundheit, Health University of Applied Sciences Tyrol, \\ 6020 Innsbruck, Austria; natalia.schiefermeier-mach@fhg-tirol.ac.at \\ 2 Department of Dietetics, FH Gesundheit, Health University of Applied Sciences Tyrol, 6020 Innsbruck, \\ Austria; sabrina.egg@fhg-tirol.ac.at (S.E.); judith.erler@fhg-tirol.ac.at (J.E.) \\ 3 Department of Nutritional Sciences, University of Vienna, 1090 Vienna, Austria; \\ verena.hasenegger@univie.ac.at (V.H.); petra.rust@univie.ac.at (P.R.); juergen.koenig@univie.ac.at (J.K.) \\ * Correspondence: anna-elisabeth.purtscher@fhg-tirol.ac.at; Tel.: +43-512-5322-76738 \\ + These authors contributed equally.
}

Received: 12 May 2020; Accepted: 28 June 2020; Published: 30 June 2020

\begin{abstract}
Dietary intake of sodium, potassium, calcium and magnesium has a strong impact on personal health. In order to understand possible correlations with regional occurrence of diseases and to develop new dietary strategies, it is necessary to evaluate food choices in defined geographic areas. The aim of this study was to analyze daily consumption and major food sources of electrolytes with an emphasis on dietary patterns. In this representative, cross-sectional study, daily foods of 463 adults were assessed with two nonconsecutive 24-h recalls. Our results show high sodium and low potassium consumption in all age groups in both men and women. Furthermore, more than half of investigated persons had low calcium, and $40 \%$ indicated low dietary magnesium intake. Only $1 \%$ of our study population reached the recommended values for all electrolytes, while $13 \%$ consumed adequate levels of three electrolytes. Moreover, $14 \%$ did not reach reference levels for any of the four minerals. A further comparison of dietary patterns and food preferences showed significant differences in major food groups including nonalcoholic drinks, fruits, vegetables, legumes, milk products, vegetable oil, bread and sweets. Our results are important for further evaluations of nutrition intake and the development of new dietary strategies.
\end{abstract}

Keywords: electrolytes; minerals; dietary intake; food sources; dietary patterns

\section{Introduction}

Sufficient intake of vitamins and minerals, preferably as part of our daily food intake, is generally recommended to prevent chronic diseases and promote health. Sodium, potassium, calcium and magnesium, also known as electrolytes, have numerous biological effects in the human body, whereas their imbalances have a strong impact on personal health. Electrolyte balance is essential for bone composition and function, muscular physiology, neuronal processes, oxygen transport, acid-base homeostasis and many other biological processes. Even small deviations in blood concentrations of electrolytes can lead to serious health problems and even increased mortality [1].

Sodium (Na) is a cation in the extracellular fluid, which largely determines its volume and osmotic pressure. It is also present in the intracellular fluid, where it contributes to the cell membrane potential and enzymatic reactions. Together with chloride, dietary sodium is mostly consumed with table salt $(\mathrm{NaCl})[2,3]$. Potassium $(\mathrm{K})$ is the most common cation of the intracellular fluid, where it is important 
for the regulation of membrane potential, maintenance of osmotic pressure, electrolyte homeostasis and acid-base-balance. Potassium also functions in controlling nerve impulses, protein biosynthesis and the conversion of blood sugar into glycogen. Although extracellular potassium only accounts for $2 \%$, both increases and decreases of extracellular potassium concentration can lead to severe neuromuscular or muscular dysfunctions [4,5]. Calcium (Ca) plays a crucial role in the formation and maintenance of bone structures and in muscle physiology. It is involved in numerous intracellular signal transduction events and is indispensable for muscle contraction, blood coagulation, hormonal system regulation, nerve impulse transmission as well as energy and fat metabolism [6]. Magnesium (Mg) is indispensable for various enzymatic reactions, protein/nucleic acid synthesis and energy metabolism [7].

It was shown that the prevalence of electrolyte imbalances in the general population may reach up to $15 \%$ [8]. Moreover, deviations in electrolyte concentrations can be associated with various diseases such as hypertension [9-13], cardiovascular diseases (CVD) [6,14-17], osteoporosis [18] and diabetes mellitus type/insulin resistance [19]. Interestingly, major differences in the geographic prevalence of these diseases have been observed in Europe, with higher rates in the eastern and north-eastern, and lower rates in the western and south-western European countries [20-23]. This "East-West gradient" was also reported for individual European countries including Germany, France and Austria [23-25]. The east-west differences within Austria were also found to be apparent regarding food intake, nutrient profile and body composition. The Austrian Nutrition Report 2012 showed that BMI, waist circumference and body fat percentage in adults were significantly higher in eastern Austria compared to western regions. Additionally, east-west differences in energy and fat intake were also reported [26].

In Austria, similarly to many other European countries, tradition plays an important role when it comes to food preferences $[27,28]$. The western Austrian region is covered by the central Alps; it is less densely populated and predominantly rural. Several traditional foods-such as typical milk products (e.g., Tyrolean cheese), meat and meat products (e.g., Tyrolean Speck), dumplings and sweet dishes (e.g., Kaiserschmarrn, Germknoedel), as well as soups and stews-are protected and registered in the Database of Origin and Registration by the European Commission [29]. They are rooted in Austria's food culture and, therefore, have an important impact on nutrient intake.

Numerous previous studies have suggested that correlations between specific foods or single nutrients with health outcomes can be inconsistent. Instead, analyses of dietary patterns may better reflect complex eating behaviors and enable correlations to be detected of food preferences with the prevalence of certain diseases. Therefore, it is important to recognize differences in dietary patterns and nutrient profiles within a certain population in order to understand possible associations with regional occurrence of nutritional deficits and diseases.

In our previous work, we identified three dietary patterns that are typical for our geographic area, with more than $60 \%$ of population following a traditional dietary pattern. This pattern was characterized by a high intake of animal products, traditional sweet dishes, dumplings, soups and stews with regular use of butter, cream and eggs. The second major dietary pattern in Western Austria, a health-conscious pattern (25\% of studied population), was represented by high intake of health-promoting foods such as plant-based products. Only $10.8 \%$ of the study population followed a western dietary pattern characterized by low consumption of plant-based products, preferential intake of processed meat, fast food and high-sugar beverages [30].

The aim of the present study was to evaluate the status of electrolyte nutritional intake in Tyrol, western Austria. We further compared electrolyte intake across various age and gender groups and combined data about individual electrolytes with food choices and dietary patterns. Our data relates electrolyte intake to actual food consumption in a tradition-rich region, and provides suggestions for future dietary improvements. 


\section{Materials and Methods}

\subsection{Study Population}

The concept, design and selection of the study population has been described before [30]. In brief, over the course of a cross-sectional study, the body composition and eating habits of 463 adults (18-64 years old) in Tyrol (Austria) were assessed between October 2014 and October 2015 by the Department of Dietetics at the Health University of Applied Sciences Tyrol. For a representative study population, Statistics Austria [31] provided the data which was based upon the registry of residents, and stratified by gender and age groups, i.e., 18-24, 25-50 and 51-64 years, as suggested by EFSA [32]. In order to obtain representative results for this region, a minimum net sample of 400 subjects was required with a significance level of $\pm 5 \%(p<0.05)$, within a confidence interval of $95 \%$ for a population of 193,386 individuals in the year of 2014. The random sample included 1376 individuals who were provided with a unique identification number. Due to nonresponses, the final number of participants was 358, and thus lower than the required minimum net sample of 400 . We also observed a higher response rate in women (32\%) than in men (20\%). Therefore, additional participants were recruited in regional companies. Exclusion criteria were based on age and permanent place of residence, as well as unusual energy intake (either too low or too high) which was determined by Goldberg cut-off points. As such, a total of 463 subjects (228 men and 235 women) completed the study.

The responsible ethics committee (The Research Committee for Scientific and Ethical Questions), an authorized committee at the UMIT (Private University for Health Sciences, Medical Informatics and Technology), reviewed and approved the study protocol (reference number: 728/13).

\subsection{Electrolyte Intake}

Over the course of one year with consideration of seasonal differences, the survey was conducted on the basis of two nonconsecutive 24-h recall. The first contact consisted of a computer-assisted personal interview (CAPI), and the second of a computer-assisted telephone interview (CATI) six weeks later. By using the computer software Globodiet with the corresponding photo book to obtain the best possible information on food consumption, the participants were asked in detail about the type and quantity of foods consumed in the previous 24-hrecalls. Reconstruction of food consumption was standardized in several phases in order to enhance the precision of memory recollection. Nutritional assessments were planned and carried out in accordance with the best practice guidelines of the EFSA [33] and the German National Consumption Study (NVSII) [34]. Standardized conditions were applied for data collection throughout the whole study. The reported foods collected during the interviews were linked to the German food composition database Bundeslebensmittelschlüssel 3.02 (BLS) [35].

After linking the reported foods to the database, electrolyte intake was determined and compared to the current reference values according to the D-A-CH societies (central European (German (D), Austrian (A), and Swiss (CH); D-A-CH) recommendations) [2] (Table 1). The assessed food items were first categorized into 40 food groups. Those food groups were defined by similarities regarding their nutrient profile (e.g., carbohydrates, dietary fiber, fats, protein) and their affiliation to common main food groups (e.g., milk and milk products, grains, vegetables) based on the classification of the BLS. Based on these food groups, we derived three dietary patterns (health-conscious, traditional and western dietary pattern) by applying a factor analysis of principal components (PCA) followed by a cluster analysis (CA) [30], and compared these patterns with each other regarding electrolyte intake. 
Table 1. Reference Values for electrolyte intake in $\mathrm{mg} / \mathrm{d}$ according to the Nutrition Societies of Germany, Austria and Switzerland (D-A-CH) [2].

\begin{tabular}{ccc}
\hline Electrolytes & Women & Men \\
\hline Sodium & 1500 & 1500 \\
Potassium & 4000 & 4000 \\
Calcium & 1000 & 1000 \\
Magnesium & & \\
age 18-24 years & 310 & 400 \\
age 25-64 years & 300 & 350 \\
\hline
\end{tabular}

Subsequently, for simplification, the forty food groups were further consolidated and reduced to 23 food groups, which contributed most to electrolyte intake. For further analysis, we used absolute sodium, potassium, calcium and magnesium intake values as compared to the D-A-CH references [2]. Additionally, we divided the study population into three groups regarding their level of electrolyte intake (low, normal, high), based on the respective recommendations.

\subsection{Statistical Analysis}

A descriptive analysis of the main characteristics of interest was performed. The full ranges of variation, arithmetic mean, standard deviation, median and interquartile (IQR) range were calculated. To determine group differences, an independent sample $t$-test was applied for gender differences, and a one-sample $t$-test was used for comparison of mean intakes of electrolytes with recommended intake values. One-way ANOVA with Bonferroni's correction was applied for age and dietary pattern groups, with the former being adjusted for gender and energy, and the latter for gender and age. Multivariate ANOVA was used for analyses of food groups and electrolyte intake. All presented $p$-values are 2-tailed; $p<0.05$ was considered significant. All analyses were performed using Excel 2016 (Microsoft Corporation, Redmond, Washington) and IBM SPSS Statistics 24 (SPSS Inc., Chicago, IL, USA). The results are presented as tables and box-and-whisker graphs (box plots). The box-and-whisker graphs depicted in the figures represent the absolute median values in mg per day (mg/day); the ends of the whisker are set at $1.5^{*} \mathrm{IQR}$ above the third quartile (Q3) and $1.5^{*} \mathrm{IQR}$ below the first quartile (Q1).

\section{Results}

\subsection{Assessment of Electrolyte Intake}

Subject characteristics are listed in Table 2. We evaluated daily intake levels of sodium, potassium, calcium and magnesium and compared them with the D-A-CH reference values. Absolute median values separately calculated for gender and age groups are depicted in figures (mg/day) and in the Supplementary Material.

Table 2. Characteristics of the study population.

\begin{tabular}{cccc}
\hline Characteristics & Women & Men & Total \\
\hline$n$ & 235 & 228 & 463 \\
Age, years * & $41.0(12.9)$ & $39.9(12.9)$ & $40.4(12.9)$ \\
Height, cm & $166.7(5.9)$ & $178.9(7.2)$ & $172.7(8.9)$ \\
Weight, kg & $65.5(13.4)$ & $81.4(14.6)$ & $73.3(16.1)$ \\
Waist circumference, cm & $85.9(11.71)$ & $91.39(11.8)$ & $88.6(12.9)$ \\
Hip circumference, cm & $100.2(10.1)$ & $100.9(7.4)$ & $100.5(8.9)$ \\
Waist-to-hip ratio & $0.86(0.06)$ & $0.90(0.07)$ & $0.88(0.07)$ \\
BMI, kg/m ${ }^{2}$ & $23.6(4.9)$ & $25.4(4.0)$ & $24.5(4.5)$ \\
Overweight/obese, \% & 28.9 & 45.6 & 37.3 \\
Smoking, \% & 21.7 & 26.8 & 24.3 \\
Migration background **, \% & 23.8 & 23.2 & 23.5 \\
Education, \% & & & \\
Elementary school & 0.4 & 0.0 & 0.2 \\
\hline
\end{tabular}


Table 2. Cont.

\begin{tabular}{cccc}
\hline Characteristics & Women & Men & Total \\
\hline Secondary school & 0.9 & 0.9 & 0.9 \\
Apprenticeship & 14.6 & 26.6 & 20.4 \\
Professional school & 17.2 & 9.0 & 13.2 \\
School with higher education & 19.7 & 24.3 & 22.0 \\
(Matura) & 34.8 & 31.1 & 33.0 \\
University & 12.4 & 8.1 & 10.3 \\
Other & 63.9 & 86.8 & 75.8 \\
Occupation, \% & 36.1 & 13.2 & 24.2 \\
Full-time & & & \\
Part-time & $*$. & & \\
* all metric variables are means with standard deviation (SD) or both parents were not born in Austria.
\end{tabular}

Differences between gender and age groups are shown in Figures 1 and 2, while values adjusted to energy intake are summarized in Table 3. The absolute median values for sodium intake were significantly higher in all persons as compared to the recommended values. Furthermore, men had a higher daily intake of sodium than women (Figure 1, Table S1). High sodium intake was independent of age, also when adjusted for gender and energy intake (Figure 2, Table 3). Daily potassium intake was significantly lower in all age groups (Figures 1 and 2). There was also a considerable difference between women and men, with women having a higher adjusted intake (Table 3).

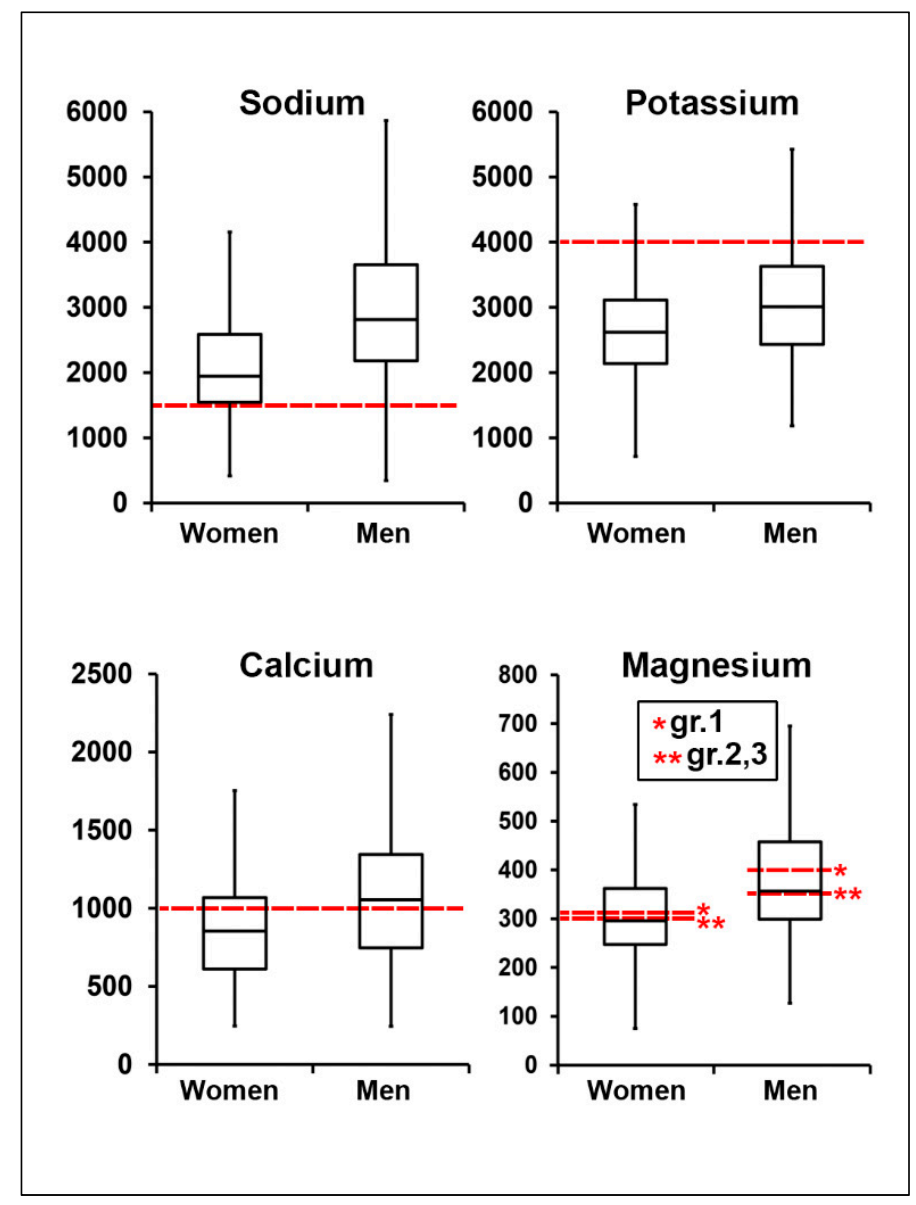

Figure 1. Median intake levels of sodium, potassium, calcium and magnesium in women and men, $\mathrm{mg}$ /day. Red dashed lines depict recommended intake levels for each electrolyte. For magnesium, red dashed lines depict reference values for different age groups: group 1 (one asterisk *gr.1) and group 2, 3 (two asterisks ** gr.2, 3) accordingly. 
Median calcium intake was lower than recommended only in women (Figure 1). However, when adjusted for energy intake, calcium consumption in men and women was equal (Table 3). The median values showed no substantial differences in all age groups (Figure 2). When adjusted for gender and energy intake, calcium intake within the first age group was significantly higher compared to the other age groups (Table 3). The intake of magnesium in different gender and age groups was not different from the recommended values (Figures 1 and 2).

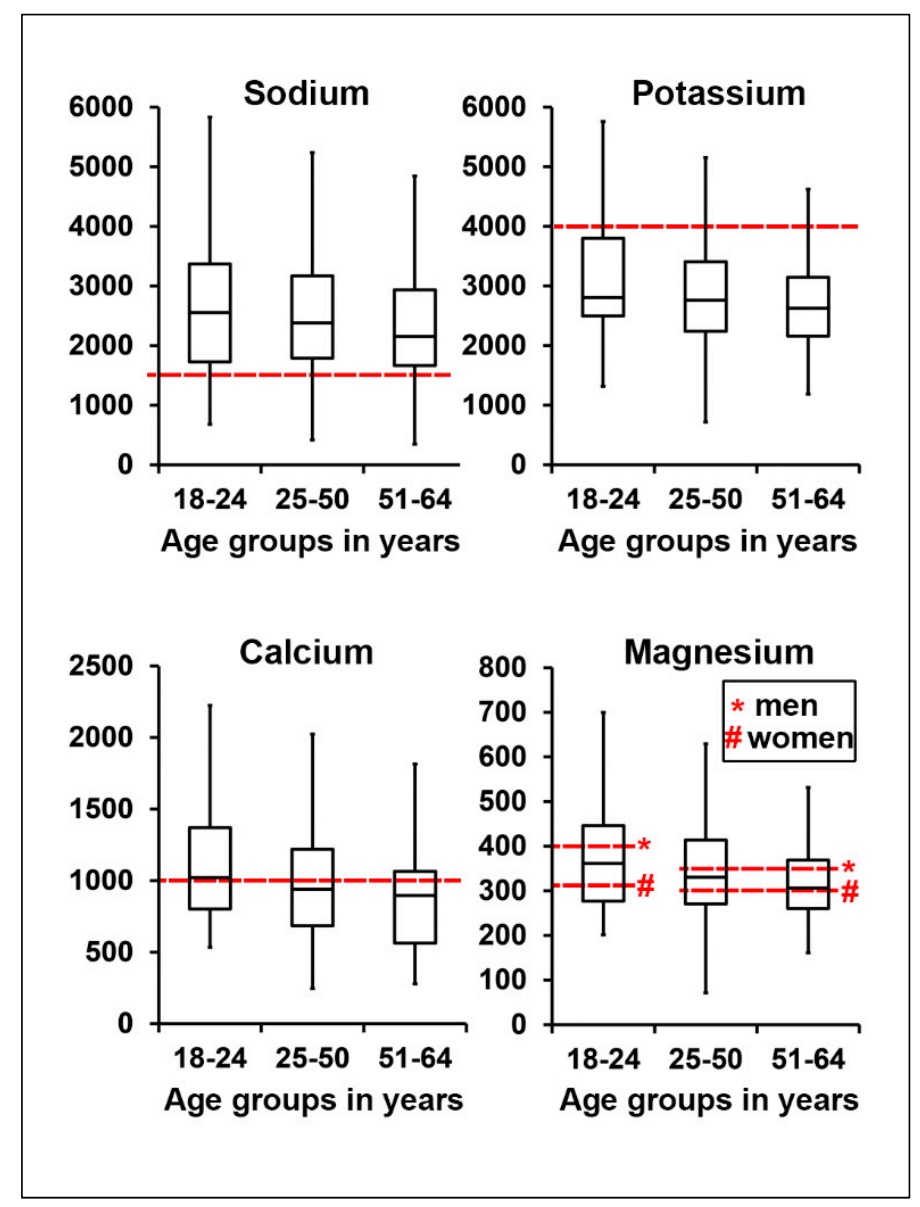

Figure 2. Median intake levels of sodium, potassium, calcium and magnesium in different age groups in $\mathrm{mg} /$ day. Red dashed lines depict recommended intake levels for each electrolyte. For magnesium, red dashed lines depict reference values for different gender groups: men (asterisk *) and women (hash sign \#) accordingly.

Further, we analyzed dietary intake in more detail. We found that the absolute median sodium intake was highest in the young men group. There was a moderate decrease in sodium consumption with age. Within the first and the third age groups, women had a lower sodium intake compared to men, with no difference in the second age group. When adjusted for energy intake, no significant difference was found (Figure 3a, Table 3). 
Table 3. Electrolyte intake in association with gender and age groups. Data shown as adjusted mean values and standard error of the mean (SE) in parentheses in $\mathrm{mg} /$ day.

\begin{tabular}{|c|c|c|c|c|c|c|c|c|}
\hline Characteristics & Sodium & $p$-Value ${ }^{1}$ & Potassium & $p$-Value & Calcium & $p$-Value & Magnesium & $p$-Value \\
\hline \multicolumn{9}{|l|}{ gender * } \\
\hline women & $2412.0(58.9)$ & & $3041.8(63.5)$ & & $983.6(23.3)$ & & $354.1(7.6)$ & \\
\hline men & 2639.8 (59.9) & 0.011 & $2824.7(64.6)$ & 0.024 & $977.5(23.7)$ & 0.862 & 352.5 (7.7) & 0.887 \\
\hline \multicolumn{9}{|l|}{ age groups ** } \\
\hline $18-24$ years & $2487.9(98.9)$ & \multirow{3}{*}{0.31} & $2922.9(106.1)$ & \multirow{3}{*}{0.658} & $1048.1(38.8)$ & \multirow{3}{*}{0.034} & 365.5 (12.7) & \multirow{3}{*}{0.319} \\
\hline $25-50$ years & $2575.7(51.6)$ & & $2961.7(55.3)$ & & $987.7(20.3)$ & & $355.0(6.6)$ & \\
\hline 51-64 years & 2438.7 (77.9) & & $2870.4(83.6)$ & & $921.0(30.6)$ & & $341.4(10.0)$ & \\
\hline \multicolumn{9}{|l|}{ women * } \\
\hline $18-24$ years & 2044.7 (107.9) & \multirow{3}{*}{0.083} & $2760.8(131.3)$ & \multirow{3}{*}{0.335} & $946.1(46.4)$ & \multirow{3}{*}{0.18} & 339.7 (15.7) & \multirow{3}{*}{0.184} \\
\hline $25-50$ years & $2159.9(57.9)$ & & $2648.0(70.5)$ & & $860.6(24.9)$ & & $308.8(8.4)$ & \\
\hline 51-64 years & $1928.8(86.5)$ & & $2829.0(105.2)$ & & 840.5 (37.2) & & $325.1(12.6)$ & \\
\hline \multicolumn{9}{|l|}{ men * } \\
\hline 18-24 years & $2926.8(169.4)$ & \multirow{3}{*}{0.899} & $3090.6(169.3)$ & \multirow{3}{*}{0.06} & $1145.0(63.2)$ & \multirow{3}{*}{0.105} & 393.1 (20.3) & \multirow{3}{*}{0.072} \\
\hline $25-50$ years & $3005.6(85.8)$ & & $3286.5(85.7)$ & & $1120.3(32.0)$ & & $401.8(10.2)$ & \\
\hline 51-64 years & $2959.5(131.3)$ & & $2922.2(131.2)$ & & $1005.3(49.0)$ & & $358.8(15.7)$ & \\
\hline
\end{tabular}

$1 p$-values for group differences are based on ANOVA for metric variables * adjusted for energy intake. ** adjusted for gender and energy intake. 
Importantly, median or mean intake values alone are not sufficient to identify persons that might be affected by mineral intake deficits/excess, and thus, that are at risk of developing electrolyte imbalances. Therefore, we additionally quantified the percentage of persons with a disparity between actual dietary intake and the respective reference values sorted by age groups. We took the reference values as "normal" intake level $\pm 10 \%$ of the error, as previously described [36,37]. Our quantification showed that $75.6-82.9 \%$ of individuals had a substantially higher sodium intake (Figure $3 \mathrm{~b}$ ), while only $5.3-6.3 \%$ of persons met the daily-recommended values (Table S2).

Low potassium intake was notable in all age groups, especially in women of all three age groups (Figure 3c). When analyzed as percentage, $74.7-89.9 \%$ of individuals had lower potassium intake, with only $5.0-10.7 \%$ reaching the recommended values (Figure 3d, Table S2).

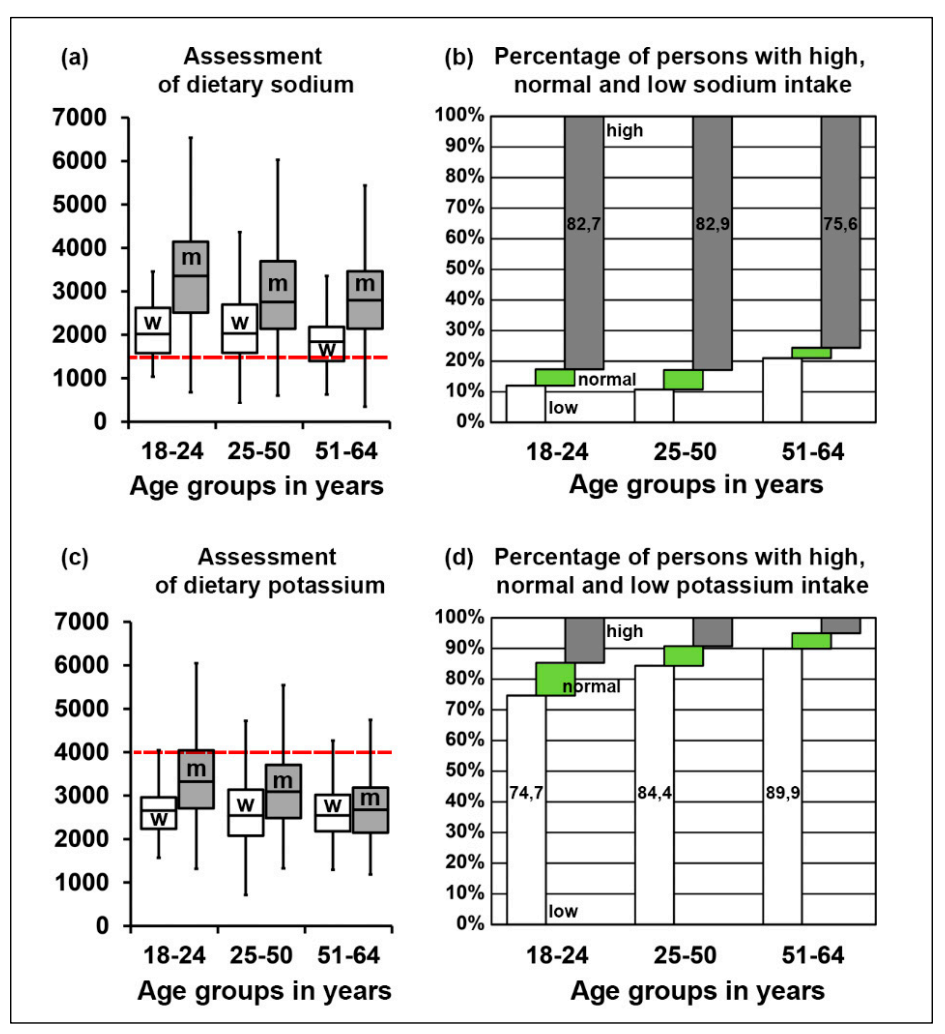

Figure 3. (a) Median intake levels of sodium in different gender and age groups in $\mathrm{mg} /$ day. (b) Percentage of persons with a discrepancy between reported sodium intake and the reference values in different age groups. (c) Median intake levels of potassium in different gender and age groups in mg/day. Red dashed lines depict the recommended intake level for sodium (a) and potassium (b); w indicates women, $\mathrm{m}$-men. (d) Percentage of persons with a discrepancy between reported potassium intake and reference values in different age groups. See also Table S2.

Although median and mean intake values for calcium and magnesium were adequate (Figure 4a, $\mathrm{c}$, Table S2), additional analysis showed that only $6.7-14.3 \%$ of individuals were in the normal range of calcium intake, whereas $26.9-46.7 \%$ were in the higher and $42.7-58.8 \%$ in the lower range, (Figure $4 \mathrm{~b}$ ). As for magnesium, 40.0 to $45.4 \%$ of persons showed adequate intake, $15.1-30.7 \%$ were in the higher and $29.3-40.3 \%$ in the lower range (Figure $4 \mathrm{~d}$, Table S2). 


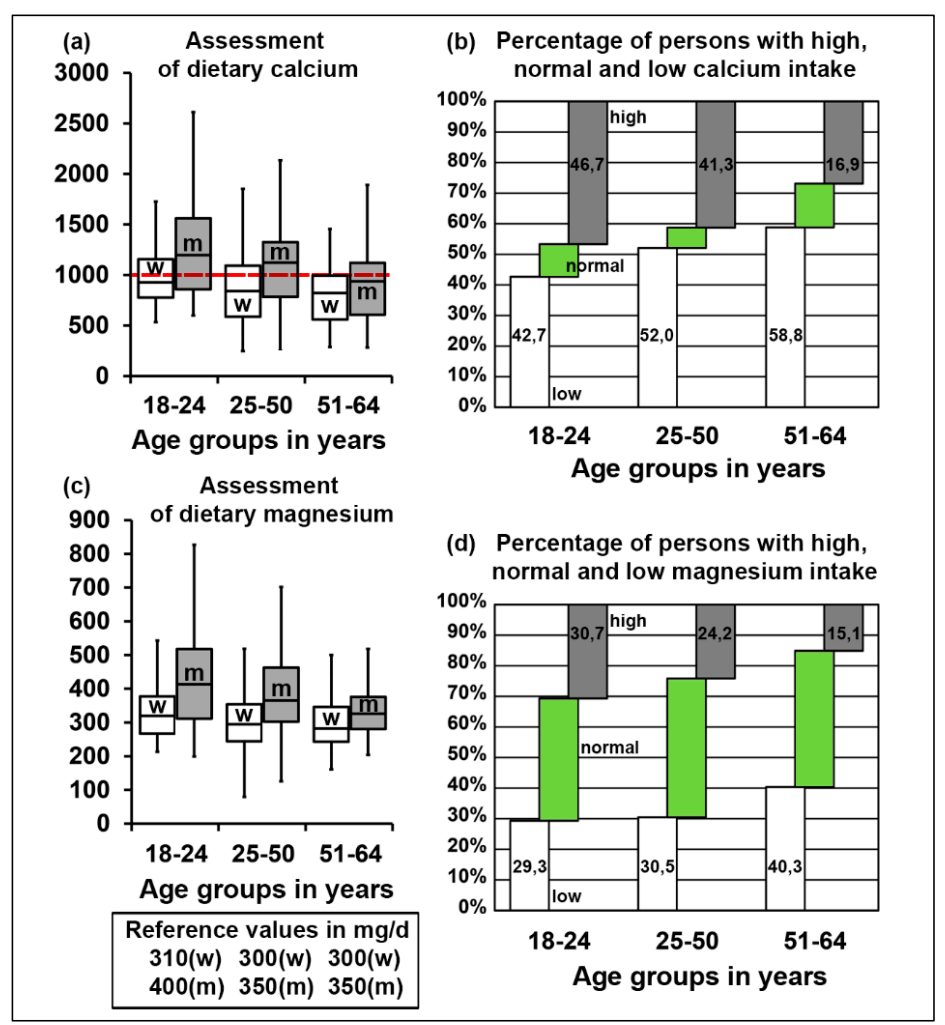

Figure 4. (a) Median intake levels of calcium in different gender and age groups in $\mathrm{mg} /$ day. Red dashed line depicts the recommended intake level for calcium, $w$ indicates women, $m-$ men. (b) Percentage of persons with a discrepancy between reported calcium intake and the reference values in different age groups. (c) Median intake levels of magnesium in different gender and age groups in mg/day. Reference values for different gender and age groups are specified in the table below, $w$ indicates women, m-men. (d) Percentage of persons with a discrepancy between reported magnesium intake and the average of reference values in different age groups. See also Table S2.

\subsection{Main Food Sources of Electrolyte Intake}

We analyzed the main food sources for all four electrolytes (Table 4). There were no considerable differences between women and men in all age groups. Bread, grains and potatoes, as well as meat, meat products, fish and condiments were the main sources of sodium. Meanwhile, 59.1\% of potassium intake came from nonalcoholic drinks (water and mineral water, tea, fruit and vegetable juice, soda and energy drinks, low sugar beverages, diet soda, coffee and green/black tea), fruits, vegetables, pulses, nuts and seeds, breads, grains and potatoes. Finally, $49.6 \%$ of calcium intake came from milk and milk products, while magnesium intake mostly came from bread, grains and potatoes, fruits, vegetables, pulses, nuts and seeds and nonalcoholic drinks.

Table 4. Main food groups contributing to electrolyte intake (shown in \%).

\begin{tabular}{lcccc}
\hline Main Food Groups & Sodium & Potassium & Calcium & Magnesium \\
\hline Water and mineral water, & 1.4 & 0.9 & 12.5 & 6.4 \\
unsweetened tea & 0.1 & 3.8 & 1.0 & 2.0 \\
Fruit and vegetable juice & 0.5 & 0.2 & 1.3 & 1.1 \\
Sodas and energy drinks & 0.1 & 0.9 & 0.3 & 0.4 \\
Low sugar beverages, diet soda & 0.6 & 8.0 & 3.7 & 8.5 \\
Coffee and green/black tea & 5.8 & 26.3 & 7.5 & 14.5 \\
Fruits, vegetables and legumes & 13.0 & 2.8 & 3.2 & 5.7 \\
White bread & 11.4 & 5.0 & 1.8 & 8.1 \\
Whole grain bread & 5.7 & 3.0 & 2.2 & 5.8 \\
Refined grains & & &
\end{tabular}


Table 4. Cont.

\begin{tabular}{lcccc}
\hline Main Food Groups & Sodium & Potassium & Calcium & Magnesium \\
\hline Whole grains & 0.3 & 1.4 & 0.4 & 3.8 \\
Potatoes & 0.6 & 6.2 & 0.7 & 3.0 \\
Milk and milk products & 3.1 & 8.2 & 19.9 & 5.7 \\
Cheese & 9.6 & 2.2 & 29.7 & 3.3 \\
Vegetable oils, nuts and seeds & 0.0 & 1.8 & 0.8 & 4.2 \\
Butter/margarine & 0.1 & 0.1 & 0.1 & 0.1 \\
Eggs & 0.1 & 0.0 & 0.0 & 0.0 \\
Meat and meat products & 11.5 & 7.8 & 1.2 & 5.3 \\
Fish and fish products & 8.9 & 2.6 & 0.6 & 2.2 \\
Sweets, desserts and cakes & 2.5 & 7.8 & 5.8 & 9.0 \\
Salty snacks and fast food & 1.5 & 2.1 & 0.5 & 1.4 \\
Alcoholic beverages & 0.3 & 2.8 & 1.0 & 4.4 \\
Condiments, sauces, spices, & 21.6 & 3.6 & 3.5 & 3.7 \\
artificial sweeteners & & & & \\
Others (soy products, & & & 1.2 & 2.4 \\
plant-based milk, soups, protein & 0.3 & & & \\
drinks, beer/wine alcohol-free) & & & &
\end{tabular}

\subsection{Electrolyte Intake among Dietary Patterns}

We previously derived three dietary patterns in adults in Western Austria and labelled them as "health-conscious", "western" and "traditional" dietary patterns [30]. In the current study, we analyzed absolute median and mean electrolyte intakes adjusted for gender and age among dietary patterns (Figure 5, Table 5).

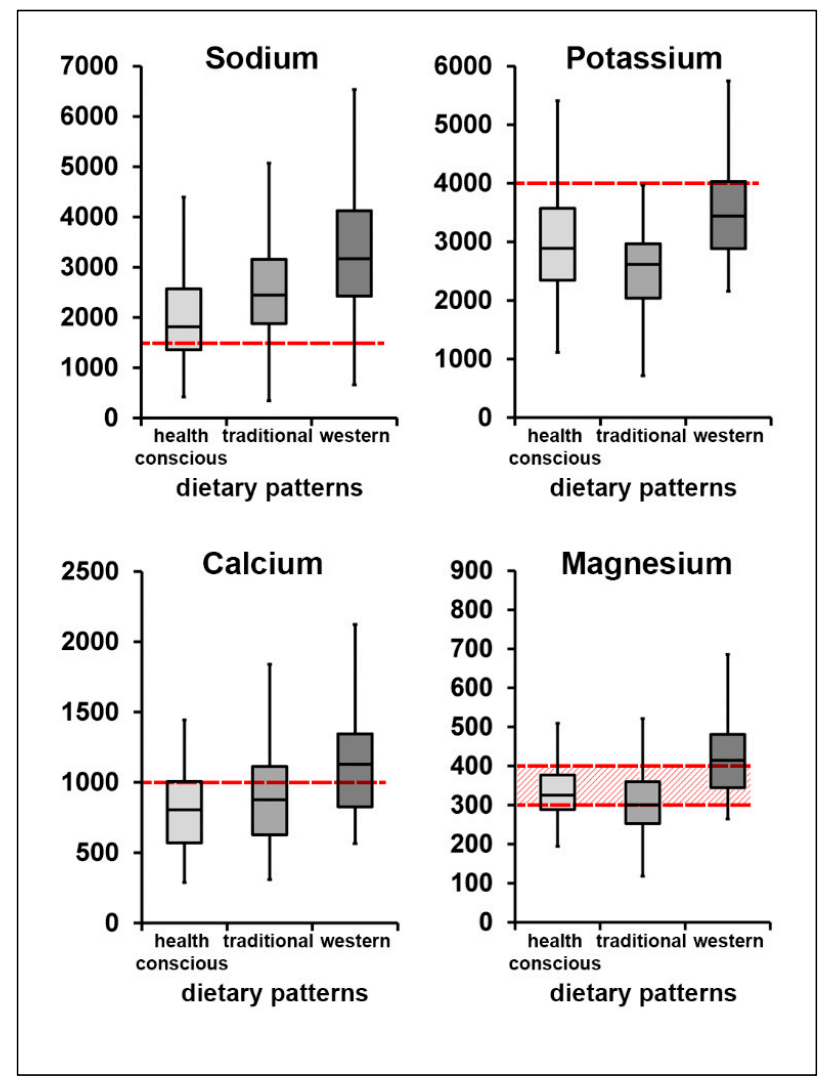

Figure 5. Median intake levels of electrolytes in different dietary patterns in mg/day. Red dashed lines depict recommended intake levels for each electrolyte. For magnesium, the red dashed pattern shows distribution of reference values for different gender/age groups. 
Our analysis showed that the absolute median intakes of all four minerals were highest in the western dietary pattern group. Median sodium and calcium intakes were lowest in the health-conscious dietary pattern group, while potassium intake was lowest in individuals following the traditional dietary pattern. When looking at the adjusted mean electrolyte intake (Table 5), sodium intake was lowest within the health conscious dietary pattern group, compared to the traditional and the western dietary pattern groups. Adjusted mean potassium and magnesium intake was lowest among individuals following the traditional dietary pattern, while calcium intake was lowest among those following the health-conscious dietary pattern. Regarding all electrolytes, we observed significant differences between dietary pattern groups when comparing adjusted values, with the exception of calcium.

We further quantified persons that reached the reference levels of all four electrolytes (D-A-CH values $+/-10 \%$ of error, as described before); we found that only 5 persons ( $1 \%$ ) in our study population did so. A further 60 persons (13\%) consumed adequate levels of three out of four electrolytes. Moreover, 66 persons $(14 \%)$ did not reach reference levels for any of the analyzed electrolytes. We further analyzed these two "polar" groups in order to identify which food groups were responsible for the observed differences (Table 6). As shown in Table 6, the prominent differences between "electrolyte-adequate" Group 2 and Group 1 were: (1) water/mineral water increase along with decrease of sodas/energy drinks; (2) high consumption of fruits/vegetables/legumes and milk/cheese products (3) decreased consumption of white bread; (4) increased consumption of vegetable oils/nuts/seeds along with decreased butter/margarine and (5) low consumption of sweets/cakes. Due to the low number of persons in both groups, we could not reliably correlate adequate electrolyte intake and previously defined dietary patterns (data not shown).

Table 5. Electrolyte intake among dietary patterns adjusted for gender and age.

\begin{tabular}{ccccc}
\hline $\begin{array}{c}\text { Characteristics and } \\
\text { Electrolyte Intake }\end{array}$ & $\begin{array}{c}\text { Health-conscious } \\
\text { Dietary Pattern }\end{array}$ & $\begin{array}{c}\text { Traditional } \\
\text { Dietary Pattern }\end{array}$ & $\begin{array}{c}\text { Western Dietary } \\
\text { Pattern }\end{array}$ & $p$-Value \\
\hline Gender, \% of women & $n=118$ & $n=295$ & $n=50$ & \\
Age, year * & 72.9 & 48.8 & 10.0 & $<0.001$ \\
Energy intake, kcal/day ** & $39.8(1.1)$ & $42.5(0.7)$ & $29.9(1.8)$ & $<0.001$ \\
Electrolyte intake** & $1901.5(61.7)$ & $2161.7(35.0)$ & $2445.2(141.2)$ & $<0.001$ \\
$\quad$ Sodium, mg/day & $2113.1(106.3)$ & $2594.9(60.3)$ & $2899.1(243.2)$ & $<0.001$ \\
Potassium, mg/day & $3289.4(108.2)$ & $2688.8(61.4)$ & $3285.5(247.6)$ & $<0.001$ \\
Calcium, mg/day & $939.7(40.2)$ & $970.2(22.8)$ & $1091.1(91.9)$ & 0.317 \\
Magnesium, mg/day & $410.3(12.5)$ & $321.8(7.1)$ & $393.5(28.6)$ & $<0.001$ \\
\hline * Values are means and standard error of the mean in parentheses. ** adjusted for gender and age.
\end{tabular}

Table 6. Comparison of main food groups contributing to electrolyte intake in participants with adequate electrolyte intake of at least three electrolytes with persons that did not reach reference values in all electrolytes.

\begin{tabular}{|c|c|c|c|}
\hline \multirow{2}{*}{ Main Food Groups } & \multicolumn{2}{|c|}{ Participants } & \multirow{2}{*}{$p$-Value } \\
\hline & Group $1(n=66)$ & Group $2(n=65)$ & \\
\hline Water and mineral water, unsweetened tea & $1410.2 \pm 138.6$ & $1952.5 \pm 131.1$ & 0.002 \\
\hline Sodas and energy drinks & $423.5 \pm 54.5$ & $100.8 \pm 51.6$ & 0.002 \\
\hline Fruits and vegetables and legumes & $199.5 \pm 37.4$ & $508.3 \pm 35.4$ & $<0.001$ \\
\hline White bread & $86.3 \pm 9.0$ & $32.6 \pm 8.4$ & 0.001 \\
\hline Milk and milk products & $70.4 \pm 25.0$ & $284.2 \pm 23.6$ & $<0.001$ \\
\hline Cheese & $32.8 \pm 11.7$ & $97.6 \pm 11.0$ & 0.004 \\
\hline Vegetable oils. nuts and seeds & $7.7 \pm 3.3$ & $24.3 \pm 3.1$ & 0.046 \\
\hline Butter/margarine & $12.8 \pm 1.6$ & $8.0 \pm 1.5$ & 0.013 \\
\hline Sweets. desserts and cakes & $149.00 \pm 16.3$ & $80.5 \pm 15.4$ & 0.034 \\
\hline $\begin{array}{c}\text { Others (soy products, plant-based milk, } \\
\text { soups, protein drinks, beer/wine alcohol-free) }\end{array}$ & $72.1 \pm 28.0$ & $208.7 \pm 26.5$ & 0.022 \\
\hline
\end{tabular}

Multivariate ANOVA model, adjusted by gender, age and energy. Values are depicted as mean value \pm standard error of the mean in $\mathrm{mg} /$ day. Group 1: persons who did not reach reference values for any of the four electrolytes. Group 2: persons that reached reference values for at least three electrolytes. 


\section{Discussion}

The present study is the first combined analysis of dietary sodium, potassium, calcium and magnesium intake in Austria. We compared nutritional intake of these four electrolytes in different gender/age groups, and described the main food sources of electrolytes according to regional dietary patterns.

It was previously shown that western dietary practices with a higher consumption of cereals and low-nutrient-density processed foods, and a lower consumption of fruits and vegetables, led to a diet high in sodium and low in potassium [38-40]. Additionally, 99.4\% of US adults were reported to consume excessive sodium, whereas less than $2 \%$ attained the recommended values for potassium [39]. Additionally, meat products (including processed meats such as ham, bacon, etc.) contribute to a high proportion of salt intake worldwide [41]. The reported potassium intakes below estimated average requirement (EAR) were 11-63\% for women and 3-37\% for men, and were highest in Spain, France, Poland and the UK, and lowest in The Netherlands [42]. Deficits in magnesium intake in the adult population (18-60 years) were also previously reported in France (32\% below EAR) and the UK (36\% below EAR).

Our results confirm and extend previous studies in Austria, Germany, the UK and the US, where $50 \%$ or more of the participants did not reach the recommendations [34,36,42-44]. In all three dietary patterns previously defined in Tyrol, the mean value of sodium intake was higher than the suggested consumption, which is also in line with our previous studies showing high consumption of salt in all regions of Austria [44,45]. Analyses of potassium, calcium and magnesium intake showed that the majority of our study population did not reach the normal intake range. When combining electrolyte intake values, only $1 \%$ of our study population reached D-A-CH recommended levels [2], while $13 \%$ consumed adequate levels of three electrolytes. Analyses of food groups showed that these individuals preferred water/mineral water over sodas/energy drinks, consumed high amounts of fruits/vegetables/legumes and milk/cheese products, preferred vegetable oils over butter and at less sweets/cakes. Due to the low number of persons, we could not reliably correlate adequate electrolyte intake with previously defined dietary patterns, but our data may help to correct existing patterns by focusing on defined food groups.

Our data may extend the discussion about the practical applicability of reference values for individual electrolytes. Thus, the optimum calcium intake remains uncertain. According to the Austrian dietary guidelines [46], three servings (about 500 g/day) of milk and dairy products (e.g., 1 glass of milk, 1 cup of yogurt, one piece of cheese) are recommended with a focus on covering calcium requirements. Guidelines from other geographic regions reduced their reference values for ecological reasons and taking into account plant-based calcium sources such as green vegetables, nuts and seeds, mineral water rich in calcium or milk alternatives [47]. Although milk and dairy products often come under criticism by the media and the public, the current scientific literature suggests that the consumption of an appropriate amount of milk and dairy products may be beneficial at all ages, with the exception of individuals with specific medical conditions such as lactose intolerance or milk protein allergy [48]. A recent review by Thorning et al. [49] summarized data on the benefits of milk products, suggesting a protective effect against type 2 diabetes and CVD, and a positive effect on bone mineral density with very few adverse effects. At the same time, studies from Asian regions report calcium intakes of less than $500 \mathrm{mg} /$ day [50], and suggested that low intake of calcium is not associated with a higher risk of bone fractures, diabetes mellitus type 2, CVD [51,52] and hypertension [35]. A recent publication by Willet et al. [53] reviewed global healthy diets and suggested that among adults, the risk of fractures is not substantially reduced with calcium intakes greater than $500 \mathrm{mg} / \mathrm{day}$. A clear association in this matter is difficult to assess, since other factors (e.g., genetics, calcium absorption, intolerances, etc.) have to be taken into account [54]. However, higher intake of calcium or milk was not associated with CVD and other diseases [17], which makes it even more difficult to establish connections between calcium intake and the aforementioned health issues. With this research 
background, our study population seems to be at low risk of calcium deficiency, despite their relatively low intake of milk and dairy products.

Evidence-based potassium recommendations have also been widely discussed in the literature. Current recommendations differ between China, the US and Europe, and are suggested to be considerably higher than current average intakes [55]. The D-A-CH reference value for potassium was recently changed from $2000 \mathrm{mg} /$ day to $4000 \mathrm{mg} /$ day, which makes it more difficult to achieve [2]. Thus, the large gap between recommended intake and the actual consumption of potassium, as we and other researchers have observed, has to be further evaluated, especially in the context of the whole diet including energy values and other minerals.

Inadequate magnesium status was previously observed in populations which consume processed-foods [43]. Our data show that the magnesium intake mean value does not differ significantly from recommended intake levels. Still, $40 \%$ of our study population did not consume enough magnesium. Most of this mineral in our study came from bread, grains and potatoes $(24.4 \%)$, fruits, vegetables, pulses, nuts and seeds (18.7\%) and nonalcoholic drinks (18.4\%). Interestingly, the average intake of whole grains, fruits, vegetables, legumes, nuts and seeds was still significantly lower than the nutritional guidelines suggest. According to the Austrian dietary guidelines [31], three portions of vegetables (375-600 g/day) and two portions of fruits (250-300 g/day) should be consumed daily. In our study population, women only reached $36.9 \%$ (1.1 portions) of the recommended vegetable and $61.0 \%$ (1.22 portions) of the recommended fruit intake, while men reached $37.3 \%(1.1$ portions) of the recommended vegetable and $43.9 \%$ (0.9 portions) of the recommended fruit intake (17). Although magnesium mean value intake in our study population was mostly within the recommended ranges, there was a clear need to optimize overall electrolyte intake by incorporating more fruits and (green) vegetables, legumes such as (soy) beans, peas, lenses and chick peas as well as whole grains such as whole grain bread, oats, or whole grain pasta. In addition, nuts and seeds such as pumpkin, sesame and sunflower seeds, as well as nuts, contribute to an adequate electrolyte intake. Taking into account that most participants follow a traditional dietary pattern, which does not include most of these products, diet optimization is challenging.

The results of our analysis allow several applicable conclusions to be made concerning the local population. Persons following traditional dietary patterns consume enough calcium and magnesium, but also eat too much salt and significantly less potassium, compared to the other dietary patterns in our study. It is therefore recommended that the consumption of plant-based foods that are widely accepted in Tyrolean cuisine be increased, e.g., white and red cabbage, potatoes, sauerkraut (pickled cabbage), seasonal local fruits and vegetables including spinach, leeks, radish, asparagus, broccoli, root vegetables, pears and apples. Persons in the group of the health-conscious dietary pattern had better sodium and potassium intakes, but did not reach the recommended calcium levels. Individuals following this dietary pattern often consume foods that are plant-based [30]; thus, if it is not possible to increase calcium intake by consuming more dairy products, alternative products, such as fortified, plant-based milk, should be included.

Strengths and Limitations: The use of two nonconsecutive 24-h recalls is one of this study's strengths, since we could consider seasonal differences and achieve the requirements of standardized conditions, as recommended by the EFSA [17]. However, the results were limited by the cross-sectional design of the study, which only allowed judgements to be made regarding possible associations but not of casual relations. Also, we could only recruit participants from the central area of Tyrol, and therefore, the results are only representative of that area. Further limitations regarding our study design are described elsewhere [14]. With lower response rates in men than in women, nonresponse bias is likely, and it was necessary to additionally recruit participants from regional companies to complete the missing gender and age groups. Therefore, these persons were not part of the original random sample. Furthermore, although known confounders were considered, residual confounding remains a possibility. In this study, the "migration background" of the person was considered when at least one of the parents was 
not born in Austria (23.5\% of participants). We did not observe any significant differences in BMI or health parameters in this group of participants [56].

Furthermore, dietary surveys are often not considered optimal for estimating a population's electrolyte intake, due to the variability of electrolyte content in the food and the use of 24-h recalls. Additionally, no blood and urine samples were taken, and thus, actual electrolyte status could not be assessed.

\section{Conclusions}

Our results add new data regarding the low potassium intake of all gender and age groups investigated in our study. We also confirm the previously described urgent need to decrease salt intake. When compared to D-A-CH recommendations, none of the dietary patterns in Tyrol was optimal for sodium, potassium, calcium or magnesium intake. Considering that more than $60 \%$ of our study participants follows a traditional dietary pattern, it is important to optimize this diet and provide adequate alternatives in food choice and/or preparation methods. Together with previously published data, our new results suggest increasing consumption of regional traditional fruits, vegetables and legumes. Further modifications of traditional cooking methods, such as replacing butter with vegetable oils when frying or sautéing foods, will clearly be beneficial. For persons following a health-conscious dietary pattern, it is important to consume more calcium-rich foods such as milk products and cheese, or to find alternative calcium sources. Further investigations are needed to develop dietary strategies which are applicable to tradition-reach geographic areas.

Supplementary Materials: The following are available online at http://www.mdpi.com/2072-6643/12/7/1956/s1, Table S1: Electrolyte intake in association with gender, age groups and dietary patterns. Data shown as mean values and standard deviation in parentheses in $\mathrm{mg} /$ day; Table S2. Percentage of persons with a discrepancy between reported intake and the recommended values for sodium, potassium, calcium and magnesium in different age groups.

Author Contributions: N.S.-M., S.E. and A.E.P. conceived the study, analyzed the data, prepared figures and tables and wrote the paper. V.H., P.R. and J.K. conceived and conducted parts of the study and supported data collection. J.E. supported data collection and analysis. All co-authors supported manuscript writing and revision. All authors have read and agreed to the published version of the manuscript.

Funding: This work was supported by the Tiroler Wissenschaftsförderung (grant no. UNI-0404/1378) and the Health University of Applied Sciences Tyrol (FH Gesundheit).

Acknowledgments: We want to thank Bernhard Perktold for his contribution to data collection.

Conflicts of Interest: The authors declare no conflict of interest.

\section{References}

1. Kear, T.M. Fluid and Electrolyte Management Across the Age Continuum. Nephrol. Nurs. J. 2017, 44, 491-496.

2. DGE; Österreichische Gesellschaft für Ernährung; Schweizerische Gesellschaft für Ernährung. Referenzwerte für die Nährstoffzufuhr, 2nd ed.; Losebl.-Ausg; Deutsche Ges. f. Ernährung: Bonn, Germany, 2016.

3. Williams, B.; Mancia, G.; Spiering, W.; Rosei, E.A.; Azizi, M.; Burnier, M.; Clement, D.L.; Coca, A.; De Simone, G.; Dominczak, A.F.; et al. 2018 ESC/ESH Guidelines for the management of arterial hypertension. Eur. Heart J. 2018, 39, 3021-3104. [CrossRef]

4. WHO. Potassium Intake for Adults and Children; World Health Organization: Geneva, Switzerland, 2015.

5. EFSA. EFSA Panel on Dietetic Products, Nutrition and Allergies. Scientific opinion on dietary reference values for potassium. EFSA J. 2016, 14, 4592. [CrossRef]

6. Vaskonen, T. Dietary minerals and modification of cardiovascular risk factors. J. Nutr. Biochem. 2003, 14, 492-506. [CrossRef]

7. Elin, R.J. Assessment of magnesium status for diagnosis and therapy. Magnes. Res. 2010, 23, S194-S198. [CrossRef]

8. Liamis, G.; Rodenburg, E.M.; Hofman, A.; Zietse, R.; Stricker, B.H.; Hoorn, E.J. Electrolyte Disorders in Community Subjects: Prevalence and Risk Factors. Am. J. Med. 2013, 126, 256-263. [CrossRef] [PubMed] 
9. He, F.J.; Li, J.; MacGregor, G.A. Effect of longer term modest salt reduction on blood pressure: Cochrane systematic review and meta-analysis of randomised trials. BMJ 2013, 346, f1325. [CrossRef]

10. Graudal, N.A.; Hubeck-Graudal, T.; Jürgens, G. Effects of Low-Sodium Diet vs. High-Sodium Diet on Blood Pressure, Renin, Aldosterone, Catecholamines, Cholesterol, and Triglyceride (Cochrane Review). Am. J. Hypertens. 2012, 25, 1-15. [CrossRef] [PubMed]

11. Resnick, L.M. Cellular calcium and magnesium metabolism in the pathophysiology and treatment of hypertension and related metabolic disorders. Am. J. Med. 1992, 93, S11-S20. [CrossRef]

12. Han, H.; Fang, X.; Wei, X.; Liu, Y.; Jin, Z.; Chen, Q.; Fan, Z.; Aaseth, J.; Hiyoshi, A.; He, J.; et al. Dose-response relationship between dietary magnesium intake, serum magnesium concentration and risk of hypertension: A systematic review and meta-analysis of prospective cohort studies. Nutr. J. 2017, 16, 26. [CrossRef] [PubMed]

13. Binia, A.; Jaeger, J.; Hu, Y.; Singh, A.; Zimmermann, D. Daily potassium intake and sodium-to-potassium ratio in the reduction of blood pressure. J. Hypertens. 2015, 33, 1509-1520. [CrossRef]

14. Polonia, J.; Monteiro, J.; Almeida, J.; Silva, J.A.; Bertoquini, S. High salt intake is associated with a higher risk of cardiovascular events. Blood Press. Monit. 2016, 21, 301-306. [CrossRef]

15. Mozaffarian, D.; Fahimi, S.; Singh, G.M.; Micha, R.; Khatibzadeh, S.; Engell, R.E.; Lim, S.; Danaei, G.; Ezzati, M.; Powles, J. Global Sodium Consumption and Death from Cardiovascular Causes. N. Engl. J. Med. 2014, 371, 624-634. [CrossRef]

16. Resnick, L.M. Cellular ions in hypertension, insulin resistance, obesity, and diabetes: A unifying theme. J. Am. Soc. Nephrol. 1992, 3 (Suppl. S4), S78-S85.

17. Chung, M.; Tang, A.M.; Fu, Z.; Wang, D.D.; Newberry, S.J. Calcium Intake and Cardiovascular Disease Risk: An Updated Systematic Review and Meta-analysis. Ann. Intern. Med. 2016, 165, 856-866. [CrossRef]

18. Bolland, M.; Bauer, D.; Huang, J.; Ou, H.-Y.; Chiu, K.C. Calcium Supplements and Fracture Prevention. N. Engl. J. Med. 2014, 370, 386-388. [CrossRef]

19. Resnick, L.M.; Barbagallo, M.; Gupta, R.K.; Laragh, J.H. Ionic basis of hypertension in diabetes mellitus. Role of hyperglycemia. Am. J. Hypertens. 1993, 6, 413-417. [CrossRef]

20. Beugelsdijk, S.; Van Schaik, T. Differences in social capital between 54 Western European regions. Reg. Stud. 2005, 39, 1053-1064. [CrossRef]

21. Romon, I.; Jougla, E.; Balkau, B.; Fagot-Campagna, A. The burden of diabetes-related mortality in France in 2002: An analysis using both underlying and multiple causes of death. Eur. J. Epidemiol. 2008, 23, 327-334. [CrossRef] [PubMed]

22. Dorner, T.; Rieder, A. Epidemiologie der koronaren Herzkrankheit und Bedeutung für die Prävention. J. Kardiol. Aust. J. Cardiol. 2005, 12, 13-15.

23. Großschädl, F.; Stronegger, W.J. Regional trends in obesity and overweight among Austrian adults between 1973 and 2007. Wien. Klin. Wochenschr. 2012, 124, 363-369. [CrossRef]

24. Müller-Nordhorn, J.; Rossnagel, K.; Mey, W.; Willich, S.N. Regional variation and time trends in mortality from ischaemic heart disease: East and West Germany 10 years after reunification. J. Epidemiol. Community Health 2004, 58, 481-485. [CrossRef]

25. Stein, K.V.; Rieder, A.; Dorner, T. East-West gradient in cardio-vascular mortality in Austria: How much can we explain by following the pattern of risk factors? Int. J. Health Geogr. 2011, 10, 59. [CrossRef]

26. Elmadfa, I.; Hasenegger, V.; Wagner, K.; Putz, P.; Weidl, N.-M.; Wottawa, D.; Kuen, T.; Seiringer, G.; Meyer, A.L.; Sturtzel, B.; et al. Österreichischer Ernährungsbericht, 1st ed.; Elmadfa: Vienna, Austria, 2012.

27. Weichselbaum, E.; Benelam, B.; Costa, H.S. Synthesis Report No 6: Traditional Foods in Europe J. EuroFIR Project Management Office/British Nutrition Foundation. United Kingdom. Available online: http: //www.eurofir.net (accessed on 6 May 2010).

28. Trichopoulou, A.; Soukara, S.; Vasilopoulou, E. Traditional foods: A science and society perspective. Trends Food Sci. Technol. 2007, 18, 420-427. [CrossRef]

29. European Commission. Database of Origin and Registration (DOOR). Available online: http://ec.europa.eu/agriculture/quality/door/list.html?\&recordStart=0\&filter.dossierNumber=\&filter. comboName=\&filterMin.milestone_mask=\&filterMin.milestone=\&filterMax.milestone__mask= $\&$ filterMax.milestone $=\&$ filter.country $=$ AT $\&$ filter.category $=\&$ filter.type $=\&$ filter.status $=\& l o c a l e=e n$ (accessed on 12 June 2012). 
30. Egg, S.; Erler, J.; Perktold, B.; Hasenegger, V.; Rust, P.; Ramoner, R.; König, J.; Purtscher, A.E. Traditional v. modern dietary patterns among a population in western Austria: Associations with body composition and nutrient profile. Public Health Nutr. 2018, 22, 455-465. [CrossRef]

31. Statistics Austria. Causes of Death at a Glance: Current Annual Results. 2017. Available online: http://www.statistik.at/web_en/statistics/PeopleSociety/health/causes_of_death/causes_of_ death_at_a_glance/index.html (accessed on 5 March 2019).

32. European Commission. ECHI Indicator Development and Documentation: Joint Action for ECHIM Final Report Part II; National Institute for Public Health and the Environment (RIVM): Bilthoven, The Netherlands, 2012.

33. EFSA. General principles for the collection of national food consumption data in the view of a pan-European dietary survey. EFSA J. 2009, 7, 1435. [CrossRef]

34. Max Rubner-Institut; Bundesforschungsinstitut für Ernährung und Lebensmittel. Nationale Verzehrsstudie II. Ernahr. Wiss. Prax. 2008, 2, 77-81.

35. Max Rubner-Institut; Bundesforschungsinstitut für Ernährung und Lebensmittel. Bundeslebensmittelschlüssel (BLS)-Version 3.02. 2019. Available online: http://www.blsdb.de (accessed on 28 January 2019).

36. Olza, J.; Aranceta-Bartrina, J.; González-Gross, M.; Ortega, R.M.; Serra-Majem, L.; Varela-Moreiras, G.; Gil, Á. Reported Dietary Intake, Disparity between the Reported Consumption and the Level Needed for Adequacy and Food Sources of Calcium, Phosphorus, Magnesium and Vitamin D in the Spanish Population: Findings from the ANIBES Study. Nutrients 2017, 9, 168. [CrossRef]

37. Archer, E.; Hand, G.A.; Blair, S.N. Validity of U.S. Nutritional Surveillance: National Health and Nutrition Examination Survey Caloric Energy Intake Data, 1971-2010. PLoS ONE 2013, 8, e76632. [CrossRef]

38. Powles, J.; Fahimi, S.; Micha, R.; Khatibzadeh, S.; Shi, P.; Ezzati, M.; Engell, R.E.; Lim, S.S.; Danaei, G.; Mozaffarian, D.; et al. Global, regional and national sodium intakes in 1990 and 2010: A systematic analysis of $24 \mathrm{~h}$ urinary sodium excretion and dietary surveys worldwide. BMJ Open 2013, 3, e003733. [CrossRef]

39. Cogswell, M.E.; Zhang, Z.; Carriquiry, A.L.; Gunn, J.P.; Kuklina, E.V.; Saydah, S.H.; Yang, Q.; Moshfegh, A.J. Sodium and potassium intakes among US adults: NHANES 2003-2008. Am. J. Clin. Nutr. 2012, 96, 647-657. [CrossRef]

40. Weaver, C.M. Potassium and Health. Adv. Nutr. 2013, 4, 368S-377S. [CrossRef] [PubMed]

41. Brown, I.J.; Tzoulaki, I.; Candeias, V.; Elliott, P. Salt intakes around the world: Implications for public health. Int. J. Epidemiol. 2009, 38, 791-813. [CrossRef] [PubMed]

42. Mensink, G.B.M.; Fletcher, R.; Gurinovic, M.; Huybrechts, I.; Lafay, L.; Serra-Majem, L.; Szponar, L.; Tetens, I.; Verkaik-Kloosterman, J.; Baka, A.; et al. Mapping low intake of micronutrients across Europe. Br. J. Nutr. 2013, 110, 755-773. [CrossRef]

43. Rosanoff, A.; Weaver, C.M.; Rude, R.K. Suboptimal magnesium status in the United States: Are the health consequences underestimated? Nutr. Rev. 2012, 70, 153-164. [CrossRef] [PubMed]

44. Rust, P.; Ekmekcioglu, C. Impact of Salt Intake on the Pathogenesis and Treatment of Hypertension. Adv. Exp. Med. Biol. 2016, 956, 61-84. [CrossRef]

45. Rust, P.; Hasenegger, V.; König, J. (Eds.) Österreichischer Ernährungsbericht 2017; Universität Wien: Vienna, Austria, 2017.

46. Bundesministerium für Gesundheit und Frauen (Ed.) Die Österreichische Ernährungspyramide; Vienna, Austria, 2016. Available online: https://broschuerenservice.sozialministerium.at/Home/Download? publicationId=617 (accessed on 28 January 2019).

47. Health Canada. Canada's Dietary Guidelines for Health Professionals and Policy Makers; Health Canada = Santé Canada: Ottawa, ON, Canada, 2019.

48. Marangoni, F.; Pellegrino, L.; Verduci, E.; Ghiselli, A.; Bernabei, R.; Calvani, R.; Cetin, I.; Giampietro, M.; Perticone, F.; Piretta, L.; et al. Cow's Milk Consumption and Health: A Health Professional's Guide. J. Am. Coll. Nutr. 2018, 38, 197-208. [CrossRef] [PubMed]

49. Thorning, T.K.; Raben, A.; Tholstrup, T.; Soedamah-Muthu, S.S.; Givens, I.; Astrup, A. Milk and dairy products: Good or bad for human health? An assessment of the totality of scientific evidence. Food Nutr. Res. 2016, 60, 32527. [CrossRef] [PubMed]

50. Balk, E.M.; Adam, G.P.; Langberg, V.N.; Earley, A.; Clark, P.; Ebeling, P.R.; Mithal, A.; Rizzoli, R.; Zerbini, C.A.F.; Pierroz, D.D.; et al. Global dietary calcium intake among adults: A systematic review. Osteoporos. Int. 2017, 28, 3315-3324. [CrossRef] 
51. Fang, A.; Li, K.; Guo, M.; He, J.; Li, H.; Shen, X.; Song, J. Long-Term Low Intake of Dietary Calcium and Fracture Risk in Older Adults With Plant-Based Diet: A Longitudinal Study From the China Health and Nutrition Survey. J. Bone Miner. Res. 2016, 31, 2016-2023. [CrossRef]

52. Kong, S.H.; Kim, J.H.; Hong, A.R.; Cho, N.H.; Shin, C.S. Dietary calcium intake and risk of cardiovascular disease, stroke, and fracture in a population with low calcium intake. Am. J. Clin. Nutr. 2017, 106, 27-34. [CrossRef]

53. Willett, W.; Rockström, J.; Loken, B.; Springmann, M.; Lang, T.; Vermeulen, S.; Garnett, T.; Tilman, D.; Declerck, F.; Wood, A.; et al. Food in the Anthropocene: The EAT-Lancet Commission on healthy diets from sustainable food systems. Lancet 2019, 393, 447-492. [CrossRef]

54. Hodges, J.K.; Cao, S.; Cladis, D.P.; Weaver, C.M. Lactose Intolerance and Bone Health: The Challenge of Ensuring Adequate Calcium Intake. Nutrients 2019, 11, 718. [CrossRef]

55. Weaver, C.M.; Stone, M.S.; Lobene, A.J.; Cladis, D.P.; Hodges, J.K. What Is the Evidence Base for a Potassium Requirement? Nutr. Today 2018, 53, 184-195. [CrossRef]

56. Egg, S.; Erler, J.; Purtscher, A.-E. Tiroler Ernährungsbericht; Fhg-Zentrum für Gesundheitsberufe Tirol GmbH: Innsbruck, Austria, 2019.

(C) 2020 by the authors. Licensee MDPI, Basel, Switzerland. This article is an open access article distributed under the terms and conditions of the Creative Commons Attribution (CC BY) license (http://creativecommons.org/licenses/by/4.0/). 